\title{
Influence of auxochrome group in disperse dyes bearing azo groups as chromophore center in the biotransformation and molecular docking prediction by reductase enzyme: Implications and assessment for environmental toxicity of xenobiotics
}

\author{
Jefferson Honorio Franco ${ }^{\mathrm{a}}$, Bianca F. da Silva ${ }^{\mathrm{a}}$, Elisangela Franciscon G. Dias ${ }^{\mathrm{b}}$, \\ Alexandre A. de Castro ${ }^{c}$, Teodorico C. Ramalho ${ }^{c}$, Maria Valnice Boldrin Zanoni ${ }^{\mathrm{a}, *}$ \\ a Institute of Chemistry, State University "Julio de Mesquita Filho"- UNESP, Araraquara, São Paulo, Brazil \\ ${ }^{\mathrm{b}}$ School of Technology, University of Campinas - UNICAMP, Limeira, São Paulo, Brazil \\ ${ }^{\mathrm{c}}$ Department of Chemistry, Federal University of Lavras - UFLA, Lavras, Minas Gerais, Brazil
}

\section{A R T I C L E I N F O}

\section{Keywords:}

Textile dye

Biotransformation

Azoreductase

Mass spectrometry

Escherichia coli

\begin{abstract}
A B S T R A C T
Synthetic azo dyes have increasingly become a matter of great concern as a result of the genotoxic and mutagenic potential of the products derived from azo dye biotransformation. This work evaluates the manner in which reducing enzymes produced by Escherichia coli (E. coli) act on three disperse dyes bearing azo groups, namely Disperse Red 73 (DR 73), Disperse Red 78 (DR 78), and Disperse Red 167 (DR 167). UV-Vis spectrophotometry, high-performance liquid chromatography with diode array detector (HPLC-DAD), and liquid chromatography mass spectrometry (LC-MS/MS) were applied towards the identification of the main products. Seven days of incubation of the azo dyes with the tested enzymes yielded a completely bleached solution. 3-4Aminophenyl-ethyl-amino-propanitrile was detected following the biotransformation of both DR 73 and DR 78 . 4-Nitroaniline and 2-chloro-4-nitroaniline were detected upon the biotransformation of DR 73 and DR 78, respectively. The main products derived from the biotransformation of DR 167 were dimethyl 3,3'-3-acetamido-4aminophenyl-azanedyl-dipropanoate and 2-chloro-4-nitroaniline. The results imply that DR 73 lost the $\mathrm{CN}^{-}$ substituent during the biotransformation. Furthermore, theoretical calculations were also carried out aiming at evaluating the interaction and reactivity of these compounds with DNA. Taken together, the results indicate that DR 73, DR 78, and DR 167 pose health risks and serious threats to both human beings and the environment at large as their biotransformation produces harmful compounds such as amines, which have been widely condemned by the International Agency for Research on Cancer.
\end{abstract}

\section{Introduction}

Annually, hundreds of new colored compounds meant for a multitude of applications in the textile, pharmaceutical, cosmetics, plastics, photographic, automotive, paper and food industries are reported in the literature. The dyes used in the textile industry exhibit a wide range of structures (including azo, chromophore, anthraquinone, arylmethane and indigo groups) and chemical properties (such as solubility and reactive functional groups) (Lewis, 2008). However, the most representative and widely used group belongs to the family of azo dyes, which are characterized by having one or more azo groups $(-\mathrm{N}=\mathrm{N})$ attached to aromatic systems (Kunz et al., 2002).

The azo dye structure can be altered through reduction, oxidation
(Osugi et al., 2006), acetylation and chlorination reactions (Oliveira et al., 2006). In addition, the dye structure can generate compounds that are even more mutagenic and relatively more harmful to the environment than the dye itself (de Aragão Umbuzeiro et al., 2004). Azo chromophores, which belong to a class of disperse dyes, have drawn a wider attention of researchers (de Aragão Umbuzeiro et al., 2005). Disperse dyes have become a huge problem to the textile industry owing to the fact that they have low solubility in water as this characteristic property favors the loss of 50\% dye during the dyeing stage (Golob and Tušek, 1999).

The conventional remediation methods currently employed are incapable of completely degrading the complex structure of these compounds. As a result, azo dyes play a significant role when it comes to the

\footnotetext{
* Corresponding author.

E-mail address: mvboldrinv@gmail.com (M.V.B. Zanoni).
} 
toxicological and ecological risks that the discharge of industrial effluents poses to the environment. The release of these improperly treated dyes into nature poses serious threats to aquatic biota and represents considerable health hazards to human beings (Lewis, 1999). Notwithstanding the vast amount of dyes used in the aforementioned range of industries, few studies have, indeed, devoted their attention towards investigating their toxicity. As such, little is known regarding the mutagenic and carcinogenic effects of these compounds. Only a small number of dyes can present acute toxicity. In other words, ingestion of these dyes could lead to immediate death (Rafii et al., 1997).

Considering the difficulties encountered in correlating toxicity and genotoxicity data of azo compounds in vitro and in vivo, it is essentially important to deepen our studies in that respect so as to devise new mechanisms of elucidation of azo dye carcinogens. In recent years, tests aimed at evaluating the toxicity of xenobiotics have been reported. Among them includes the Ames test which is a bacterial test used for detecting whether compounds under investigation (dyes, for instance) are toxic or not (Brandon et al., 2003) making it a successful tool used for mutagenesis analyses of xenobiotics, since it detects a wide variety of mutagenic compounds and mimetizing the reactions that occur in the intestinal microflora (Novotný et al., 2006).

Franco et al. evaluated the mutagenic potential of the DR 73, DR 78 and DR 167 dyes using the Ames test for TA 98 and TA 100 strains. The dyes were analyzed both in the presence of the $S 9$ mixture so as to simulate the biotransformation mediated by CYP isoenzymes and in the absence of exogenous metabolic activation in order to simulate the biotransformation mediated by the intestinal microflora reducing enzymes (azoreductase and nitroreductase) produced by Salmonella typhimurium. Disperse Red 73 was considered the most mutagenic dye, considering its mutagenic potential of $30 \mathrm{rev} / \mu \mathrm{g}$ with TA 98 and 34 $\mathrm{rev} / \mu \mathrm{g}$ with TA 100 strain, both in the absence of metabolism (-S9). In the presence of S9, the DR 73 presented a reduction in the mutagenic potential after metabolic activation. DR 78 and DR 167 exhibited low mutagenic activity in both the absence and presence of metabolic activity (P-450). Based on the above results, the Salmonella / microsome test can be used as an important tool to predict the effects of the ingestion of azo dyes dispersed on human health, clearly indicating that the dyes can be biotransformed (Franco et al., 2018).

The intestine is, indeed, a possible target organ for carcinogenesis after a person is exposed to azo dyes (Sweeney et al., 1994). The intestinal microflora of humans and other animal species can reduce the azo groups of xenobiotics (Cerniglia et al., 1982). However, the specific organisms of the intestinal microflora that take part in azo dye reduction are yet poorly understood (Brown, 1981). The reduction reaction is responsible for the production of aromatic amines, which can act as human carcinogens (Cerniglia et al., 1986; Brüschweiler et al., 2014; Govindwar et al., 2014).

Biotransformation or degradation of an azo dye may occur through a variety of microorganisms, including the aerobic and anaerobic bacteria (Chung and Stevens, 1993). Bacterial degradation of azo dye is usually initiated through the enzymatic biotransformation process with the aid of azoreductase which promotes the cleavage of azo bonds (Zimmermann et al., 1982; Ogawa et al., 1978).

Azoredutase is one of the major reductase type enzymes, which is known to have the ability to metabolize azo dyes ingested by humans into aromatic amines. These aromatic amines are mostly produced by the intestinal microflora or by enzymes present in the cytoplasm of mammalian cells, such as the enzymes belonging to the cytochromes P450 family (Zanoni et al., 2013).

The docking procedure is clearly a crucial starting point for the commencement of the analysis of substrates and inhibitors in an enzyme active site (Thomsen and Christensen, 2006). This methodology enables us to make predictions regarding the occurrence of near attack conformations (NAC) (Hur and Bruice, 2003), which present the most reactive ground state conformations, deemed to be of great importance. This technique enables one to explore the reactive environment, taking<smiles>CCN(CCC#N)c1ccc(/N=N\c2ccc([N+](=O)[O-])cc2C#N)cc1</smiles><smiles>CCN(CCC#N)c1ccc(/N=N\c2ccc([N+](=O)[O-])cc2Cl)cc1</smiles><smiles>CCCCN(CC(C)=O)c1ccc(/N=N\c2ccc([N+](=O)[O-])cc2Cl)c(NC(C)=O)c1</smiles>

Fig. 1. Structure of Disperse Red 73 (DR 73) (I), Disperse Red 78 (DR 78) (II) and 167 Disperse Red (DR 167) (III) dyes.

into account the influence of neighboring residues, which could, in principle, modulate the stability of the ligand in the active site, thereby leading to effective reactions (Hur and Bruice, 2003; Luo and Bruice, 2004). In this sense, the molecular docking calculations could be helpful for assessing the influence exerted by substituents in the disperse dyes molecules in the binding modes and interactions with azoredutase active sites.

Based on the results obtained with the Ames Test by Franco et al., it is extremely important to study the metabolites formed by the reduction of the azo group. Thus, the present work investigates the action mechanism of enzymes present in the intestinal microflora of azo dyes which possess selected substituents including the following: Disperse Red 73, Disperse Red 78 and Disperse Red 167 (chemical structure in Fig. 1). To this end, we investigated the biotransformation products generated by the action of reducing enzymes, such as azoredutase, produced by the anaerobic Escherichia coli bacteria. The dyes and their biotransformation products were evaluated by UV-Vis spectrophotometry, high performance liquid chromatography with diode array detector (HPLC-DAD) and mass spectrometry (LC-MS/MS). Furthermore, theoretical calculations were performed so as to confirm the interaction and reactivity of the substituents bonded to the azo group with respect to the azoredutase enzyme. These three dyes were selected for study because of their chemical similarity with only few different ligands. Therefore, we were interested in knowing if azo compounds with similar chemical structures but with few different ligands $\left(\mathrm{CN}^{-}\right.$and $\mathrm{Cl}^{-}$) could provide more or less toxic metabolites after biotransformation process.

\section{Experimental}

\subsection{Materials and reagents}

Disperse Red 73 (DR 73), Disperse Red 78 (DR 78), and Disperse Red 167 (DR 167) were obtained from Classic Dyestuffs Inc. Fraction S9 was acquired from Moltox INc. The mineral salts medium (MM) used in all the batch experiments, conducted at $\mathrm{pH} 7$, contained $\mathrm{K}_{2} \mathrm{HPO}_{4}$ $\left(1.6 \mathrm{~g} \mathrm{~L}^{-1}\right), \mathrm{KH}_{2} \mathrm{PO}_{4}\left(0.2 \mathrm{gL}^{-1}\right),\left(\mathrm{NH}_{4}\right)_{2} \mathrm{SO}_{4}\left(1.0 \mathrm{~g} \mathrm{~L}^{-1}\right), \mathrm{MgSO}_{4} \cdot 7 \mathrm{H}_{2} \mathrm{O}$ $\left(0.2 \mathrm{~g} \mathrm{~L}^{-1}\right), \mathrm{FeSO}_{4} \cdot 7 \mathrm{H}_{2} \mathrm{O}\left(0.01 \mathrm{~g} \mathrm{~L}^{-1}\right), \mathrm{NaCl}\left(0.1 \mathrm{~g} \mathrm{~L}^{-1}\right)$, and $\mathrm{CaCl}_{2} \cdot 2 \mathrm{H}_{2} \mathrm{O}$ $\left(0.02 \mathrm{~g} \mathrm{~L}^{-1}\right)$ purchased from Sigma Aldrich. The rich mineral medium (MMR) consisted of MM supplemented with $100 \mathrm{mg} \mathrm{L}^{-1}$ of each dye and $1 \mathrm{~g} \mathrm{~L}^{-1}$ of glucose (Sigma Aldrich). The MMR was placed in an autoclave at $121^{\circ} \mathrm{C}$ (Himach CR 21 Hitach) for $15 \mathrm{~min}$. 
The chromatographic eluents included acetonitrile (ACN), supplied by Sigma Aldrich, and water purified in a MilliQ System (Millipore).

\subsection{Bacterial strains}

The standardized E. coli (ATCC 25922) bacterial strain used in this study belonged to the culture collection of the Microbiology Laboratory of the Technology Faculty of the State University of Campinas, Brazil. The pure culture was kept frozen in mineral oil. The $E$. coli strain was reactivated on Nutrient Agar plates containing $100 \mathrm{mg} \mathrm{L}^{-1}$ of each azo dye at $37^{\circ} \mathrm{C}$ for $24 \mathrm{~h}$ (Franciscon et al., 2010).

\section{3. $D R 73, D R 78$, and $D R 167$ biotransformation using Escherichia coli}

Following the growth of E.coli on nutrient Agar plate, the E.coli microbial biomass $(20 \%)$ was inoculated with $1 \mathrm{gL}^{-1}$ of glucose in bottles containing MM and mixed with $100 \mathrm{mg} \mathrm{L}^{-1}$ of each dye. The samples were incubated in static conditions at $37^{\circ} \mathrm{C}$ for seven days; decoloration was monitored by UV-Vis spectroscopy on a daily basis. After this procedure, the samples were filtered through a $0.22 \mu \mathrm{m}$ membrane, and the supernatant was used for chemical analyses (Elisangela et al., 2009).

\subsection{Optimized conditions for analysis of $D R 73, D R 78$, and $D R 167$ in culture medium containing Escherichia coli}

The samples were transferred into $50 \mathrm{~mL}$ centrifuge tubes and centrifuged for $15 \mathrm{~min}$ at $10.000 \mathrm{rpm}$. All the samples analyzed by LC-MS/ MS were subjected to solid-phase extraction with a Strata-X cartridge, $200 \mathrm{mg} / 3 \mathrm{~mL}$, Phenomenex. The cartridges were conditioned using $3 \mathrm{~mL}$ of methanol (MeOH), which was followed by the addition of $3 \mathrm{~mL}$ of ultrapure water (condition). Subsequently, $10 \mathrm{~mL}$ of the sample was loaded and washed with $10 \mathrm{~mL}$ of water. The sample was eluted with $2 \mathrm{~mL}$ of $\mathrm{ACN}$ and $2 \mathrm{~mL}$ of $\mathrm{H}_{2} \mathrm{O} / \mathrm{MeOH} 50: 50(\mathrm{v} / \mathrm{v})$ mixture and dried under a slow $\mathrm{N}_{2}$ flow. The sample was then resuspended in $10 \mathrm{~mL}$ of ACN. Afterwards, an aliquot of sample was taken out and analyzed by LC-MS/MS.

\subsection{Instrumentation}

The spectrophotometric measurements were carried out on a Hewlett Packard (HP) spectrophotometer model 8453, from 200 to $800 \mathrm{~nm}$. The solutions were placed in a 5-mL quartz cuvette (Hellma) with optical path of $1.0 \mathrm{~cm}$.

An ultra-Turrax homogenizer, a Centrifuge Excelsa Baby model I 206, and a Vortex IKA were used in the Electroanalytical Chemistry Laboratory (NDcom). An ultracentrifuge Hitachi HIMAC CP90WX was used in the Organic Chemistry Laboratory (mass spectrometry).

\subsection{High performance liquid chromatography}

HPLC analysis was carried out using a chromatograph (Shimadzu, model LC-10AT) equipped with two pumps and an automatic injector (injection volume of $20 \mu \mathrm{L}$ ) coupled to a diode array detector (model SPD-M10AVP). The chromatograms were investigated in the range of 200-800 nm; the maximum wavelengths selected for analysis of the hair dyes DR 73, DR 78, and DR 167 were 509, 483, and $510 \mathrm{~nm}$, respectively. The HPLC analysis was performed in a reversed-phase column (Shimadzu CLC-ODS, C18, $25 \mathrm{~cm} \times 4.6 \mathrm{~mm} \times 5 \mu \mathrm{m}, 100 \mathrm{~A}$ ) preceded by a pre-column (Luna Phenomenex, C18, $1 \mathrm{~cm} \times 4.6 \mathrm{~mm} \times$ $5 \mu \mathrm{m}, 100 \mathrm{~A}$ ). Prior to the analysis, all the solutions were filtered through a $0.45-\mu \mathrm{m}$ PTFE filter. The best experimental conditions under the optimized isocratic mode were as follows: mobile phase $=\mathrm{ACN}$ / $\mathrm{H}_{2} \mathrm{O} 70: 30(\mathrm{v} / \mathrm{v})$, flow rate $=0.8 \mathrm{~mL} \mathrm{~min}^{-1}$, and column temperature $=30^{\circ} \mathrm{C}$. The analysis time was $20 \mathrm{~min}$. All the analyses were carried out in triplicate. UV-Vis spectra in the hydrodynamic mode were also recorded for each peak of the chromatograms.

\section{7. $L C-M S / M S$}

The products obtained during the treatment of textile dyes with the reaction medium containing the $E$. coli bacteria were determined by liquid chromatography-mass spectrometry (LC-MS/MS) in a 1200 Agilent Tchnologies HPLC coupled to a 3200 QTRAP mass spectrometer (Linear Ion Trap Quadrupole LC/MS/MS Mass Spectrometer), AB SCIEX Instruments operating in the positive mode with Turbolon Spray ionization.

The chromatographic analyses were performed with the aid of a $5 \mu \mathrm{m}$ Luna C-18 column (2) (measuring $250 \mathrm{~mm} \times 4.6 \mathrm{~mm}$ ). $\mathrm{A} \mathrm{H}_{2} \mathrm{O}$ / ACN mixture $20: 80(\mathrm{v} / \mathrm{v})$ containing $0.1 \%$ formic acid at a flow rate of $1 \mathrm{~mL} \mathrm{~min}^{-1}$ was used as the mobile phase in the isocratic mode. The injection volume and the column temperature were $10 \mu \mathrm{L}$ and $25^{\circ} \mathrm{C}$, respectively. The analyses lasted $10 \mathrm{~min}$.

Mass spectrometry (3200 QTRAP) was conducted with the full scan experiment in the enhanced mode (EMS, enhanced mass scan with the linear ion trap analyzer). The ionization conditions and the source parameters were previously optimized for each dye pattern. Each individual dye was optimized by direct infusion (syringe with automatic flow rate of $10 \mu \mathrm{Lin}^{-1}$ ) at a concentration of $500 \mathrm{ppb}\left(\mathrm{MeOH} / \mathrm{H}_{2} \mathrm{O}\right.$ $1: 1(\mathrm{v} / \mathrm{v})$ containing $0.1 \%$ formic acid). Ionization was obtained with the Turbolon Spray source (electrospray) operating in the positive mode. Fragment ion experiments (EPI, enhanced product, also using the linear ion trap ion) were conducted aiming at obtaining structural information regarding the possible products. The collision energy for these experiments ranged from 20 to $50 \mathrm{~V}$.

LC-MS/MS analyses were carried out in order to investigate the presence of aromatic amines as intermediates in the biotransformation experiments involving E. coli and the dyes DR 73, DR 78, and DR 167. The target compounds, such as aniline, 4-chloroaniline, 2-chloro-4-nitroaniline, and 4-nitroaniline, were optimized by direct infusion of $0.1 \mathrm{mg} \mathrm{L}^{-1}$ of these compounds (in $\mathrm{MeOH} / \mathrm{H}_{2} \mathrm{O} 1: 1(\mathrm{v} / \mathrm{v})$ containing $0.1 \%$ formic acid) at $10 \mu \mathrm{L} \mathrm{min}^{-1}$. To carry out the qualitative analysis, SRM (selected reaction monitoring) experiments were performed, and two transitions of each compound were subjected to monitoring.

\subsection{Computational methodology}

\subsubsection{Docking procedures}

The 3D structures of the dyes were constructed using the Gaussian 09 software and the partial charges of the atoms were also calculated. The compounds were fully optimized at the Density Functional Theory (DFT) level, with B3LYP density functional and 6-31G (d,p) basis set, employing the CHELPG methodology (Gonçalves et al., 2011). Each compound was docked inside the crystal structure of AzoR (azoreductase) from the Escherichia coli (PDB code: 2D5I, resolution: $2.2 \AA$ ) (Ito et al., 2006). The docking studies were carried out using the Molegro Virtual Docker (MVD ${ }^{\circledR}$ ) software (Thomsen and Christensen, 2006), taking into account the same procedures previously reported in the literature (Guimarães et al., 2011; Matos et al., 2011; da Cunha et al., 2012; Silva et al., 2015). Furthermore, the amino acid residues within a radius of $5 \AA$ were kept flexible. Due to the nature of the docking methods, the calculations generated 50 poses (conformation and orientation) for each dye.

The MolDock scoring function employed in the MVD program comes from the piecewise linear potential (PLP), a simplified potential with its parameters fitted to protein-ligand structures (Thomsen and Christensen, 2006; Ramalho et al., 2010). The docking scoring function values, $\mathrm{E}_{\text {score, }}$ are defined by Eq. (1):

$E_{\text {score }}=E_{\text {inter }}+E_{\text {intra }}$

where, $E_{\text {inter }}$ is the intermolecular interaction energy of the ligandprotein and $E_{i n t r a}$ being the internal energy of the ligand. The $E_{i n t e r}$ is 

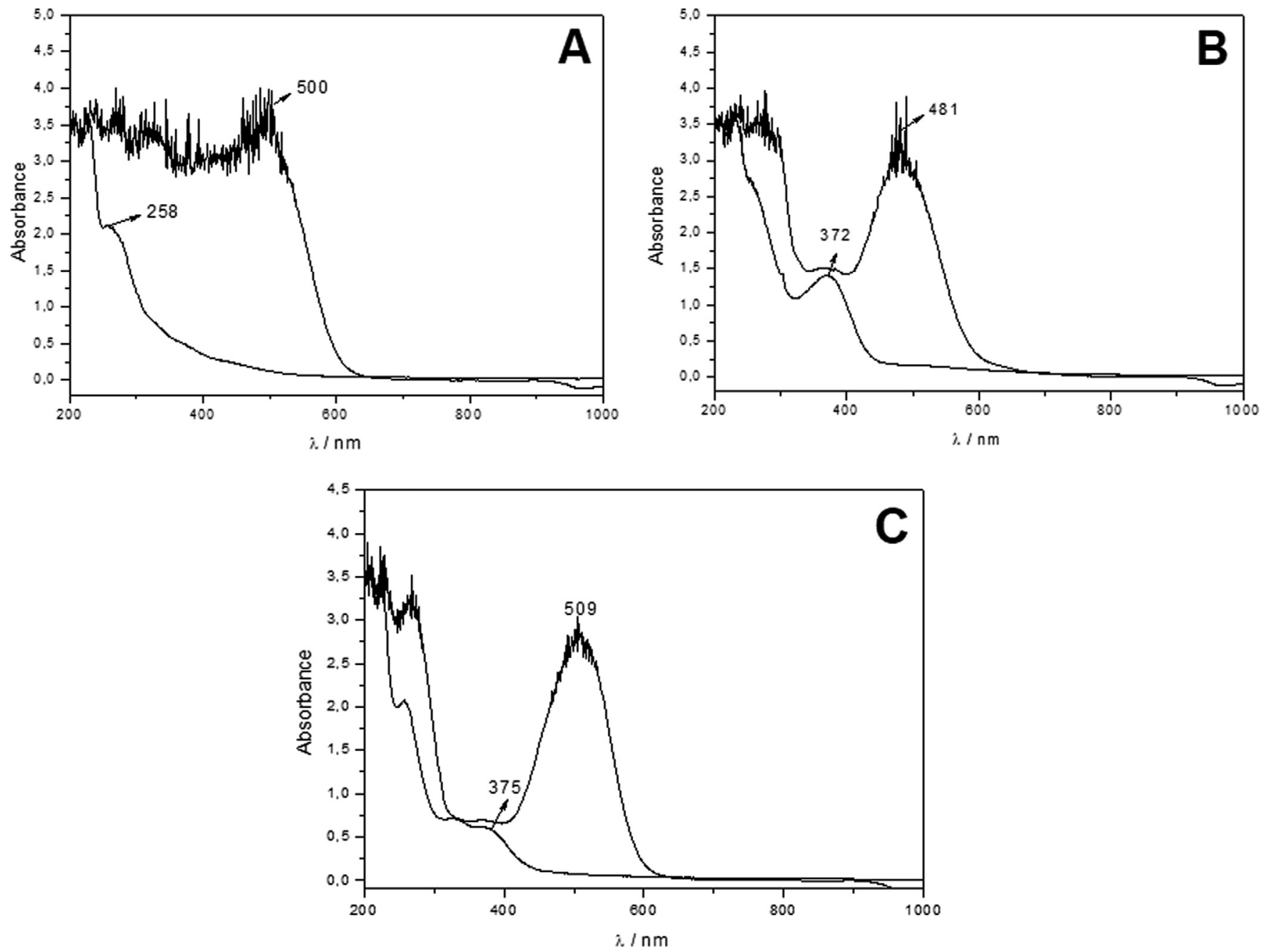

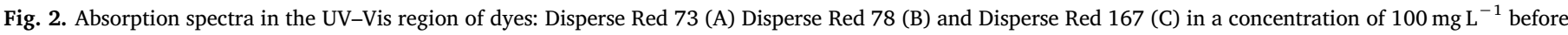
and after incubation with $E$. coli.

shown in Eq. (2):

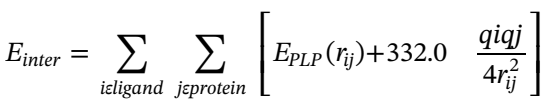

The EPLP term represents the PLP (piecewise linear potential) energy, which consists of the use of two different parameter sets, described as follows: one for the approximation of the steric term (Van der Waals) among atoms, and the other potential for the hydrogen binding. The second term $\left(332.0 \frac{q i q j}{4 r_{i j}^{2}}\right)$ is related to the electrostatic interactions among overloaded atoms. It is a Coulomb potential with a dielectric constant dependent on the distance $(D(r)=4 r)$. The numerical value of 332.0 is responsible for the electrostatic energy unit to be given in kilocalories per molecule (Thomsen and Christensen, 2006). The $q i$ and $q j$ terms represent the charges of the atoms $i$ and $j$, respectively. The $r_{i j}$ term indicates the interatomic distance between the atoms $i$ and $j$ (Thomsen and Christensen, 2006).

The $E_{\text {intra }}$ is shown in Eq. (3).

$E_{\text {intra }}=\sum_{\text {isligand }} \sum_{\text {jeligand }} E_{P L P}\left(r_{i j}\right)+\sum_{\text {flexiblebonds }} A\left[1-\cos \left(m . \theta-\theta_{0}\right)\right]+E_{\text {clash }}$

The first part of the equation (double summation) is among all pairs of atoms in the ligand, removing those that are connected by two bonds. The second term characterizes the torsional energy, where $\theta$ is the torsional angle of the bond and $\theta_{0}$ is its corresponding value in the equilibrium. The average of the torsional energy bond contribution is used when several torsions could be determined. The last term, $\mathrm{E}_{\text {clash}}$, assigns a penalty of 1.000 if the distance between two heavy atoms (more than two bonds apart) is shorter than $2.0 \AA$; it does not account for infeasible ligand conformations (Thomsen and Christensen, 2006). The docking search algorithm which is applied in the MVD program considers an evolutionary algorithm, the interactive optimization techniques which are inspired by Darwinian evolution theory, and a new hybrid search algorithm called guided differential evolution. This hybrid search algorithm mechanism combines the differential evolution optimization technique with a cavity prediction algorithm during the search process, thus allowing a fast and accurate identification of potential binding modes (poses) (da Cunha et al., 2004; Thomsen and Christensen, 2006).

\subsubsection{PM6 semi-empirical calculations}

While semi-empirical methods are based on the Hartree-Fock formalism, they perform several approximations by obtaining some parameters from empirical data. Through this category of techniques, the approach involving large systems with many atoms is rendered feasible. This allows one to conduct theoretical studies with proteins, DNA, enzymes and other molecular systems with thousands of atoms as widely employed these days. The semi-empirical methods emerged in 1931 with the studies carried out by Michael Polanyl and Henry Eyring (Morgon and Coutinho, 2007), which sought to address the quantum 
theory tied up with empirical results, producing satisfactory results. The PM6 semi-empirical method was found to be appropriate for calculating the binding energies of the dyes in the azoreductase active site.

In short, properties such as enthalpy of formation, dipole moment, ionization potential, angles, dihedral and bond lengths are all included. The reference database is required to be extended to a representative group of molecules that present good accuracy regarding the empirical results of its properties (Morgon and Coutinho, 2007). Clearly, recent extensions of PM3 (PM6) seem to represent substantial improvements (Lewars, 2011). The calculations were performed in the azoreductase active site within a radius of 5 Á, considering the water molecules as well as the amino acid residues included within this limit.

The interaction energy $\left(\Delta E_{\text {int }}\right)$ is calculated based on Equation 4 with contributions from the free Azo Reductase enzyme $\left(\Delta \mathrm{E}_{\mathrm{AzoR}}\right)$, free dye $\left(\Delta \mathrm{E}_{\text {dye }}\right)$ and enzyme-dye system $\left(\Delta \mathrm{E}_{\text {system }}\right)$.

$\Delta \mathrm{E}_{\text {int }}=\Delta \mathrm{E}_{\text {system }}-\left(\Delta \mathrm{E}_{\text {Dye }}+\Delta \mathrm{E}_{\text {AzoR }}\right)$

\subsubsection{Reactivity parameters and Frontier Effective-for-Reaction Molecular} Orbital (FERMO) analysis

The contribution of an atom to a Molecular Orbital (MO) is calculated as the sum of the square of the expansion coefficients of the atomic orbitals centered on this atom (Silva et al., 2017). This method is employed in order to obtain a better rationalization of the influence of MOs of each dye, mainly in relation to the azo group. It also enable us to predict the reactivity with the enzyme in a biotransformation process. These calculations were performed at the DFT level, with B3LYP density functional and 6-31G (d, p) basis set.

\section{Results}

\subsection{Decoloration of $D R 73, D R 78$, and $D R 167$ by $E$. coli}

Fig. 2 illustrates the UV-Vis spectra obtained for (A) DR 73, (B) DR 78, and (C) DR 167 at $100 \mathrm{ppm}$ before and after incubation with $E$. coli at $36^{\circ} \mathrm{C}$ for seven days. To mimic the biotransformation processes, the spectra were obtained without any dilution of the sample. The characteristic absorption bands of DR 73, DR 78, and DR 267 were 500, 481, and $509 \mathrm{~nm}$, respectively. It is worth pointing out that the bands were found to be suppressed upon carrying out incubation with $E$. coli; this outcome indicates complete decoloration. New absorbance bands that emerged at 258, 372, and $375 \mathrm{~nm}$ for DR 73, DR 78, and DR 167, respectively, were attributed to products with aromatic character (Şahin et al., 2007; dos Santos et al., 2007; Saratale et al., 2011).

\section{2. $D R 73, D R 78$, and $D R 167$ degradation products generated by E. coli}

\subsubsection{HPLC-DAD}

Fig. 3 (A-C, peak 2) shows the typical chromatograms obtained using DAD detector for (A) DR73, (B) DR78, and (C) DR 167 at $50 \mathrm{ppm}$ under the following conditions: column C18, mobile phase $=\mathrm{ACN} / \mathrm{H}_{2} \mathrm{O}$ $80: 20(\mathrm{v} / \mathrm{v})$, flow rate $=1.0 \mathrm{~mL} \mathrm{~min}^{-1}$, and $\mathrm{T}=30^{\circ} \mathrm{C}$. The insert in Fig. 3, curves A-C, contains the corresponding UV-Vis spectrum derived from the DAD detector for each dye. The well-defined peaks revealed retention times of 4.72, 7.08, and $5.24 \mathrm{~min}$ for DR 73, DR 78, and DR 167 , respectively. Following the incubation of DR 73, DR 78, and DR 167 with $E$. coli for seven days, these peaks disappeared from the chromatograms, while new peaks emerged at retention times of 4.04, 6.03 , and $6.03 \mathrm{~min}$, respectively. This suggests that the action of the bacterium completely changed the azo group in the chemical structure of the azo dye. In other words, the results indicate that azoreductase reduced the azo group in the dye, a fact confirmed by the appearance of a new peak chromatographic referring to a new product generated at a lower wavelength retention time different from that presented for the standard dye.
Overall, the enzymatic reaction promoted cleavage of the azo group, which in turn promoted total discoloration of the dye solutions. As new products arose in the process, LC-MS/MS studies were conducted with the aim of obtaining more information about the nature of these new products.

\subsection{Identification of $D R 73, D R 78$, and $D R 167$ reduction products by $L C$ - MS/MS}

A novel LC-MS/MS method, which was fully developed in this work, was applied towards the profiling of unknown metabolites obtained from the bacterial biotransformation of the textile dyes DR 73, DR 78 and DR 167. Initially, the LC-MS/MS method was used for the detection of metabolites through the acquisition of data using full MS scan in the range of $m / z 200$ to $m / z 800$. The identification of potential metabolites were carried out by the comparison of total ion chromatograms and mass spectra obtained for the control samples and the biotransformation samples. Detected target ions, which were not present in the control samples, were regarded as potential metabolites.

Given that the total ion chromatogram covers a wide mass range and shows a fairly high background which undermines the visual detection of new peaks in the chromatogram, the approach of using background substraction was applied to all samples analyses.

It is important to note that all other chromatographic peaks detected in the extracted ion chromatograms, with the exception of the chromatographic peak of the biotransformation product, refer to components of the reaction medium and they were detected in the control samples. The identification and structural analysis were performed using fragment ion experiments (MS/MS). Thus, the MS/MS mass spectrum (Fragment ion chromatogram) was performed to confirm that the chromatographic peaks of interest were new metabolites formed.

After incubation with $E$. coli for seven days, the original chromatographic peaks attributed to the dyes disappeared. This confirmed the complete biotransformation of DR 73, DR 78, and DR 167 into other products. These products were absent in the control samples.

Table 1 summarizes the products obtained for each disperse dye after seven days of reaction with $E$. coli.

The LC-MS/MS chromatographic profile obtained in the EMS mode (scanning ions) for DR 73 (Fig. S1), DR 78 (Fig. S2), and DR 167 (Fig. S3) at $20 \mathrm{ppm}$, in the positive mode, revealed that DR 73, DR 78, and DR 167 presented peaks at 4.57, 6.72, and $6.17 \mathrm{~min}$ with $\mathrm{m} / z$ 349, 359, and 506, respectively, which corresponded to the protonated molecule $[\mathrm{M}+\mathrm{H}]^{+}$.

Fig. S4 shows the total ion chromatogram profile obtained by LC-MS for the DR 73 dye before and after reaction with E. coli in Fig. S4A and Fig. S4B, respectively. By comparing the chromatograms obtained for biotransformation and control samples, one will observe that both chromatograms show a band around $3.06 \mathrm{~min}$. This band is related to glucose and other compounds present in the culture medium and found to be responsible for the growth of bacteria (nutrient agar). In the control sample (see Fig. S4A), the DR 73 was detected at $4.56 \mathrm{~min}(\mathrm{~m} / \mathrm{z}$ 349). The substrate is, however, absent in the biotransformed sample; this outcome, indeed, confirms the complete biodegradation of the substrate (see Fig. S4B).

A potential metabolite with $m / z 190\left([\mathrm{M}+\mathrm{H}]^{+}\right)$was observed at $1.81 \mathrm{~min}$ (Fig. S4B). The mass $189 \mathrm{Da}$ corresponded to the ion with $\mathrm{m} / \mathrm{z}$ $190\left([\mathrm{M}+\mathrm{H}]^{+}\right)$and indicated cleavage of the azo bond, which yielded the amine. This metabolite was further confirmed through the analysis of extracted ion chromatogram and fragment ions (EPI) of $m / z 319$ (Fig. S5). The MS/MS mass spectrum profile (S5B) revealed $m / z 136$ as a more intense fragment ion (base peak), related to the loss of an ethyne $(26 \mathrm{Da})$ and ethylene $(28 \mathrm{Da})$. Other ions that were generated included the one with $m / z 173$, related to the loss of amine $\left(-\mathrm{NH}_{3} \mathrm{Da}\right)$, and the ones with $m / z 149$ and $m / z 121$, which are attributed to the elimination of a ketenimine and an alkene, respectively. Ketenimines are organic compounds that share a common functional group and have the general 

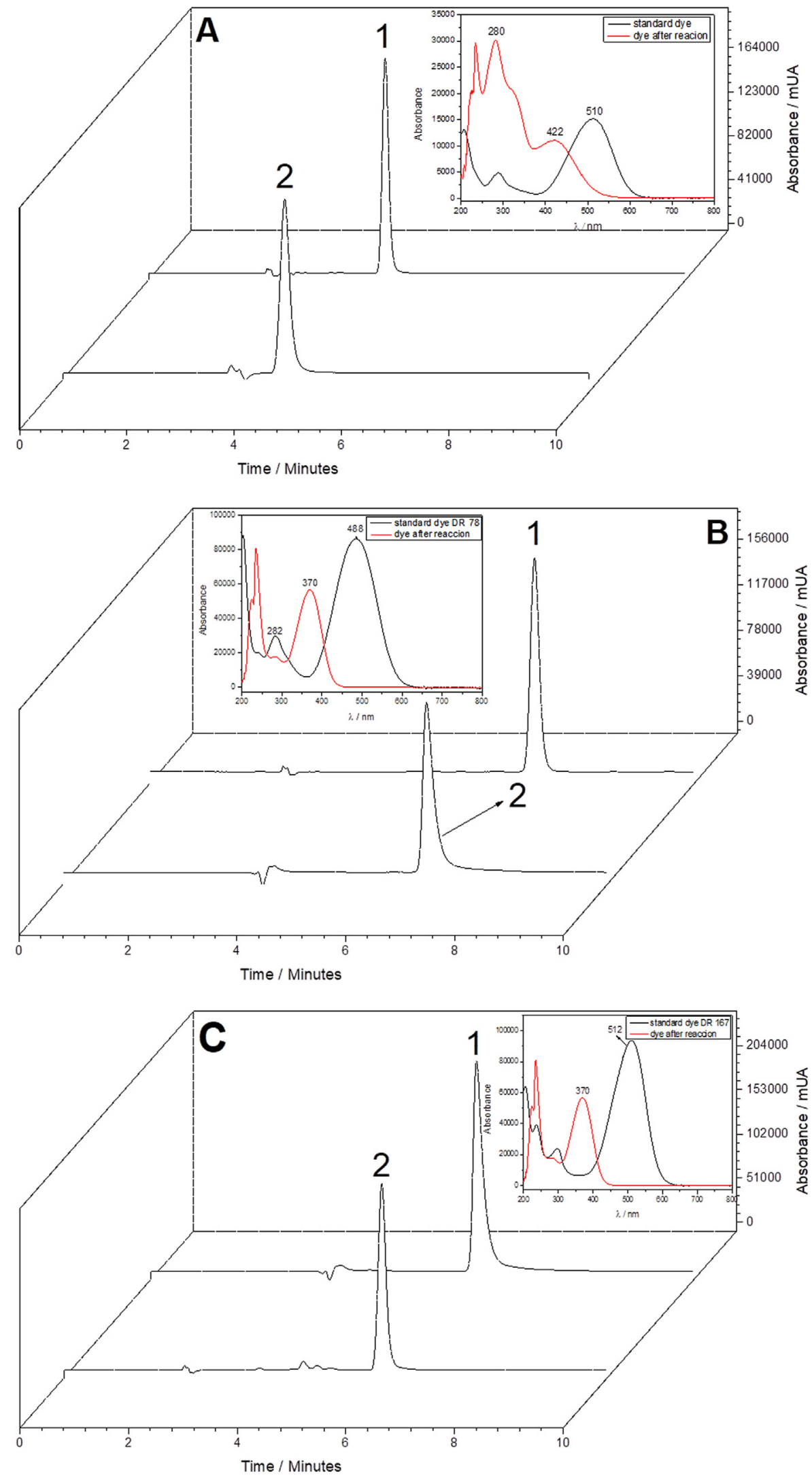

Fig. 3. Chromatogram obtained by HPLC-DAD: $50 \mathrm{ppm}$ of textile dyes after biotransformation with the bacterium $E$. coli ( peak 1) and 50 ppm of standard dyes (peak 2): Disperse Red 73 (A), Disperse Red 78 (B) and Disperse Red 167 (C) in acetonitrile obtained under the following conditions: $\mathrm{C} 18$, mobile phase 80:20 ACN/ $\mathrm{H}_{2} \mathrm{O}$. flow rate $=1.0 \mathrm{~mL} \mathrm{~min}^{-1} . \mathrm{T}=30^{\circ} \mathrm{C}$. Detection: $\lambda=510 \mathrm{~nm} ; 488 \mathrm{~nm}$ and $512 \mathrm{~nm}$ corresponding to: Disperse Red 73, Disperse Red 78 and Disperse Red 167, respectively. 
Table 1

Biotransformation products of Disperse Red 73, Disperse Red 78 and Disperse Red 167 dyes.

Dyes $\quad$ Metabolites $\quad m / z \quad \begin{gathered}\text { Retention } \\ \text { time (min) }\end{gathered}$

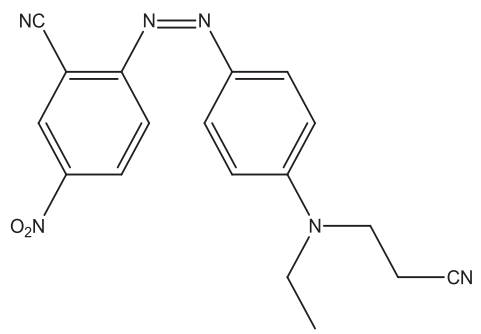

349.2

Disperse Red 73

DR 73

Biotransformation products 3-((4-aminophenyl)(etyl)amino)propanitrila

$190.1 \quad 1.81$

139

3.28

358.1

6.72

190.1

1.87 
Table 1 (continued)

\begin{tabular}{l}
\hline DR 78 \\
Biotransformation \\
products
\end{tabular}

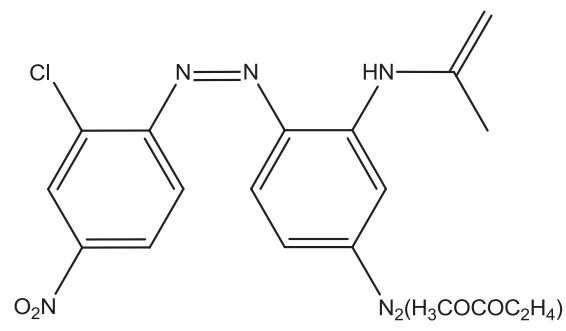

2-chloro-4-nitroaniline

Disperse Red 167

DR 167

Biotransformation products

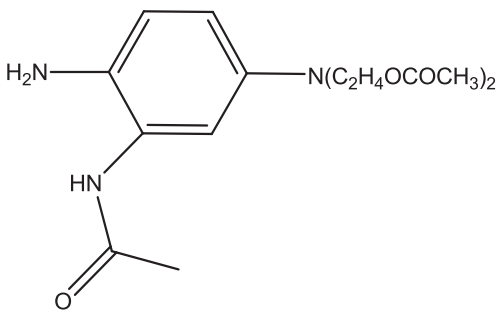

506,2

Dimethyl 3,3`-((3-acetamido-4aminophenyl)azanediyl)dipropanoato<smiles>Nc1ccc([N+](=O)[O-])cc1Cl</smiles>

2-chloro-4-nitroaniline

structure $\mathrm{R}_{1} \mathrm{R}_{2} \mathrm{C}=\mathrm{C}=\mathrm{NR}_{3}$. Based on the obtained fragment ion spectrum (Scheme 1), 3,4-aminophenyl-ethyl-amino-propanitrile was found to be the main product derived from DR 73 biotransformation. Enzymes produced by $E$. coli, possibly azoreductase, metabolized DR 73 to form an ion with $\mathrm{m} / \mathrm{z} 190$ through the cleavage of the azo dye group.

LC-MS/MS in the SRM mode detected the target compounds with higher sensitivity and selectivity. A peak attributed to 4-nitroaniline, with $m / z$ 139, was found at $3.28 \mathrm{~min}$ (Fig. S6). This peak confirmed cleavage of the azo bond, with consequent formation of the degradation product with $m / z 190$ (as discussed before) and of the product with $m / z$ 139 (4-nitroaniline) (Table 1). The presence of 4-nitroaniline shows the occurrence of a secondary enzymatic reaction. The formation of amine took place following the elimination of the cyanide group through the action of the nitrile hydratase enzyme, which is also present in E. coli.

The metabolites possibly derived from DR 78 dye were investigated. Fig. S7 shows the total ion chromatogram obtained by LC-MS for DR 78 prior to (Fig. S7A) and following the reaction with E. coli (Fig. S7B). The total ion chromatograms are found to exhibit intense peaks at low retention times of $1.70 \mathrm{~min}$ and $2.51 \mathrm{~min}$ (Fig. S7A) and $2.64 \mathrm{~min}$ (Fig.
S7B), which are derived from the reaction medium. Although the other peaks observed in Fig. S7B (substrate in the presence of $E$. coli) are similar to those of the control sample (sample containing the substrate with no bacteria), both chromatograms show a peak at approximately $6.75 \mathrm{~min}$, the chromatographic band relating to the DR 78 (Fig. S2).

An in-depth analysis of the biotransformation sample demonstrated the presence of a potential metabolite with $\mathrm{m} / \mathrm{z} 190\left([\mathrm{M}+\mathrm{H}]^{+}\right)$and peak at $1.87 \mathrm{~min}$ (Fig. S7B), which was not present in the sample without bacteria (Fig. S7A). This metabolite was further confirmed through the analysis of extracted ion chromatogram and fragment ions (EPI) of $m / z 190$ (Fig. S8) and was attributed to 3-4-aminophenylethyl-amino-propanitrile.

Another peak found at $4.59 \mathrm{~min}$ with $\mathrm{m} / \mathrm{z} 173$ was assigned to 2chloro-4-nitroaniline and confirmed by the SRM mode (Fig. S9). The enzyme acted towards the cleavage of the azo group in DR 78, which directly yielded the products with $m / z 190$ and $m / z 173$ (Table 1 ).

The fragment ion mass spectrum obtained after DR 78 biotransformation resembled the spectrum derived from the biotransformation of DR 73. In this context, the product with $\mathrm{m} / \mathrm{z} 190$ at 


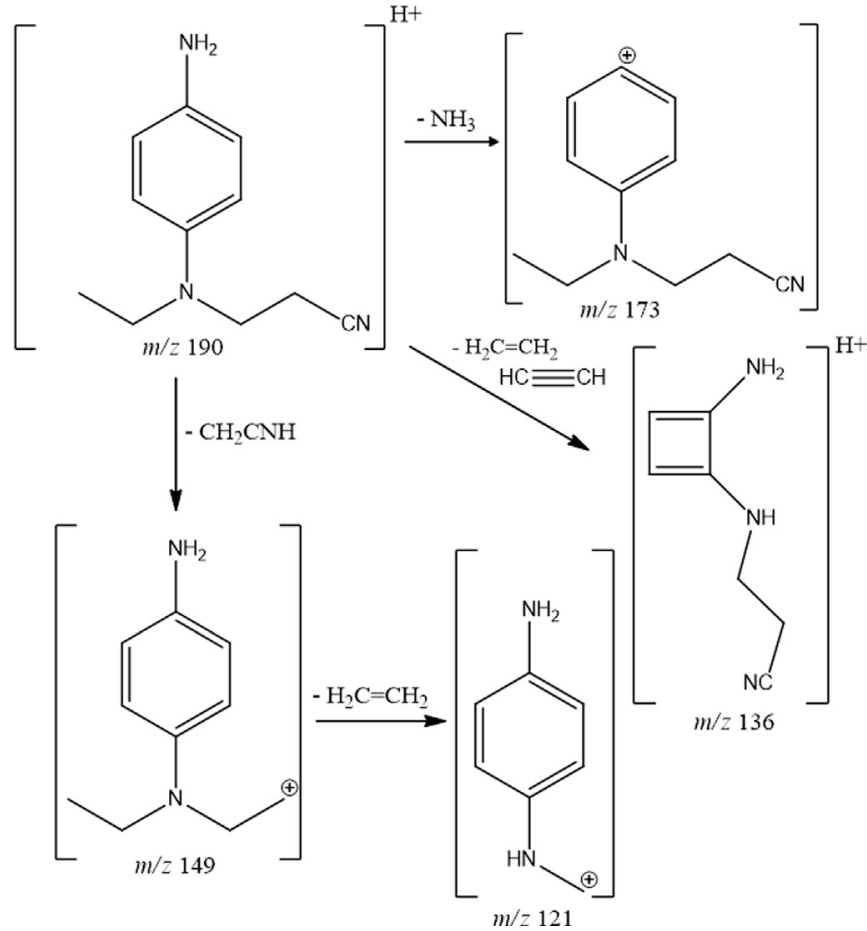

Scheme 1. Fragmentation proposal for the metabolite $m / z 190$, formed after reaction with $100 \mathrm{ppm}$ of standard DR 73 incubated with $E$. coli under static conditions at $30^{\circ} \mathrm{C}$ for seven days.

$1.87 \mathrm{~min}$, corresponding to 3,4-aminophenyl-ethyl-amino-propanitrile, was derived from both DR 73 and DR 78 biotransformations, as can be noted from the fragmentation patterns (see Scheme 1).

While 3,4-aminophenyl-ethyl-amino-propanitrile was a product of both DR 73 and DR 78 metabolisms, differences were observed in DR 73 and DR 78 biotransformations using $E$. coli enzymes. The formation of 4-nitroaniline, which was derived from DR 73, indicated loss of cyanide. In the case of DR 78 metabolism, the chloro substituent was maintained in the product derived from the cleavage of the azo group.

Fig. S10 shows the total ion chromatograms obtained by LC-MS for DR 167 before and after reaction with E. coli (see Fig. S10A and Fig. S10B, respectively). In Fig. S10A, DR 167 is detected as $m / z 506$ ([M $+\mathrm{H}]^{+}$) with retention time of $6.11 \mathrm{~min}$, which was not detected in the biotransformation sample (Fig. S10B). By analyzing the total ion chromatogram obtained before and after reaction with $E$. coli, a peak at 2.47 min with $\mathrm{m} / \mathrm{z} 338\left([\mathrm{M}+\mathrm{H}]^{+}\right)$indicates the formation of a new potential metabolite (Fig. S10B). This product was further confirmed through the analysis of extracted ion chromatogram and fragment ions (EPI) of $m / z 338$ (Fig. S11). The ion with $m / z 338$ was derived from the cleavage of the azo group. The mass $337 \mathrm{Da}$ refers to the metabolite that resulted from the rupture of the azo bond, yielding an amine $(\mathrm{m} / \mathrm{z} 338$ $\left.[\mathrm{M}+\mathrm{H}]^{+}\right)$. MS/MS analysis enabled us to propose a structure for the detected product. The MS/MS mass spectrum of $m / z 338$ (Fig. S11B) displayed base peak with $\mathrm{m} / \mathrm{z} 87$, which was attributed to the structure $\mathrm{C}_{2} \mathrm{H}_{4} \mathrm{OCOCH}_{3}$. The other detected fragment ions were $\mathrm{m} / z 296$, related to loss of the acetyl functional group $\left(-\mathrm{COCH}_{3}\right) ; \mathrm{m} / z 252$, associated with the loss of $\mathrm{C}_{2} \mathrm{H}_{4} \mathrm{OCOCH}_{3}$ bound to the tertiary amine of DR 167; and $m / z 236$, attributed to the loss of $-\mathrm{NH}_{3}$ from the fragment ion $m / z$ 252. Based on the fragment ion spectrum, the proposed product was dimethyl 3,3'-3-acetamido-4-aminophenyl-azanediyl-dipropanoate (337 Da, detected in the positive mode as $m / z 338$ ). For the purpose of confirming the azo reduction, another peak at $4.58 \mathrm{~min}$ with $\mathrm{m} / \mathrm{z} 173$, related to 2-chloro-4-nitroaniline and confirmed by the SRM mode, was detected (Fig. S12). Scheme 2 illustrates the fragmentation proposed for the product derived from DR 167. The enzymatic action led to two degradation products with $m / z 190$ and $m / z 173$ (Table 1). The latter corresponded to 2-chloro-4-nitroaniline and indicated that, unlike the $\mathrm{CN}^{-}$substituent in DR 73, the chloro substituent was not removed from DR 167 during the biotransformation.

The Disperse Red 78 bears chlorine as one of the aromatic ring substituents and Disperse Red 167 contains chlorine and a bulky disubstituted amine $\left(\mathrm{C}_{2} \mathrm{H}_{4} \mathrm{OCOCH}_{3}\right)$ group whereas Disperse Red 73 contains a cyanide atom in its structure. The substituents in DR 78 and DR 167 probably decreased the electron density in the azo group, consequently diminishing their mutagenicity as compared to DR 73 . These data corroborate with the study of Ferraz et al. (2011) that demonstrated that chlorine substitution greatly reduce the mutagenic potential of Disperse Red 13 when compared to Disperse Red 1 (Ferraz et al., 2011). According to Levine (1985), electron donating and the withdrawal of groups from the aromatic ring markedly affected the coupling reaction by way of inductive and resonance effects (Levine, 1985).

In order to prove our theory, a theoretical calculation study of the interaction of dye structures with DNA was performed.

\subsection{Theoretical insights}

\subsubsection{Molecular docking results}

Docking calculations were carried out aiming at evaluating the binding modes and interactions. Essentially, molecular mechanics based methods involving docking procedures are suitable tools for adjusting ligands at target sites and for estimating intermolecular interaction energies (affinity). For the docking procedures, a cavity prediction algorithm based on a 3D box was used to generate the binding sites of the azoreductase enzyme using Molegro Virtual Docker program (Fig. S13) (Thomsen and Christensen, 2006). The docking results are presented in Table 2.

By observing the energy values shown in Table 2, it is quite interesting to note that all dyes have interacted very well in the azoreductase active site, showing affinity and stability in the active cavity. These results suggest that all the dyes investigated in this study can be promptly biotransformed, giving rise to diverse metabolites. It is important to keep in mind that lower intermolecular interaction energy values lead to a better affinity between enzyme and ligand. Table 2 shows the hydrogen bonds (H-bonds) that occurred between each dye and the amino acid residues/water molecules presented in the enzyme active site. These details are deemed necessary because these interactions contribute towards the stability of the ligand when docked in the enzyme. Hydrophobic interactions in addition to environmental effects modulate the stability and conformation of the ligand in the enzyme active site.

From our theoretical findings, Disperse Red 73 was found to have the best interaction energy with the enzyme, its energy value being about $-80.92 \mathrm{kcal} \mathrm{mol}^{-1}$. Disperse Red $78\left(-72.81 \mathrm{kcal} \mathrm{mol}^{-1}\right)$ came second in terms of energy value, followed by Disperse Red 167 $\left(-67.20 \mathrm{kcal} \mathrm{mol}^{-1}\right)$. By performing these theoretical calculations, the replacement of the cyanide group with the chlorine atom was found to increase the interaction energy value between DR 73 and DR 78. The energy difference between them was $8.11 \mathrm{kcal} \mathrm{mol}^{-1}$. It is worth noting that both the cyanide group in DR 73 and the chlorine atom in DR 78 performed no hydrogen bonding in the azoreductase active site. Other factors, such as structural and electronic effects (Fig. S14) could take place, thereby contributing towards modulating the stability of DR 73 in the enzyme active site.

Disperse Red 73 performed two hydrogen bondings, one with the Gly141 amino acid residue and the other one with water molecule. Besides displaying the same interactions, DR 78 also presented one additional interaction with water molecule (Fig. S15).

Disperse Red 78 and Disperse Red 167 presented similar energy values, with a difference of only $5.61 \mathrm{kcal} \mathrm{mol}^{-1}$. With regard to DR 167 , an energy difference of $13.72 \mathrm{kcal} \mathrm{mol}^{-1}$ was observed between it and DR 73. DR 167 presented a larger number of hydrogen bonds, with 


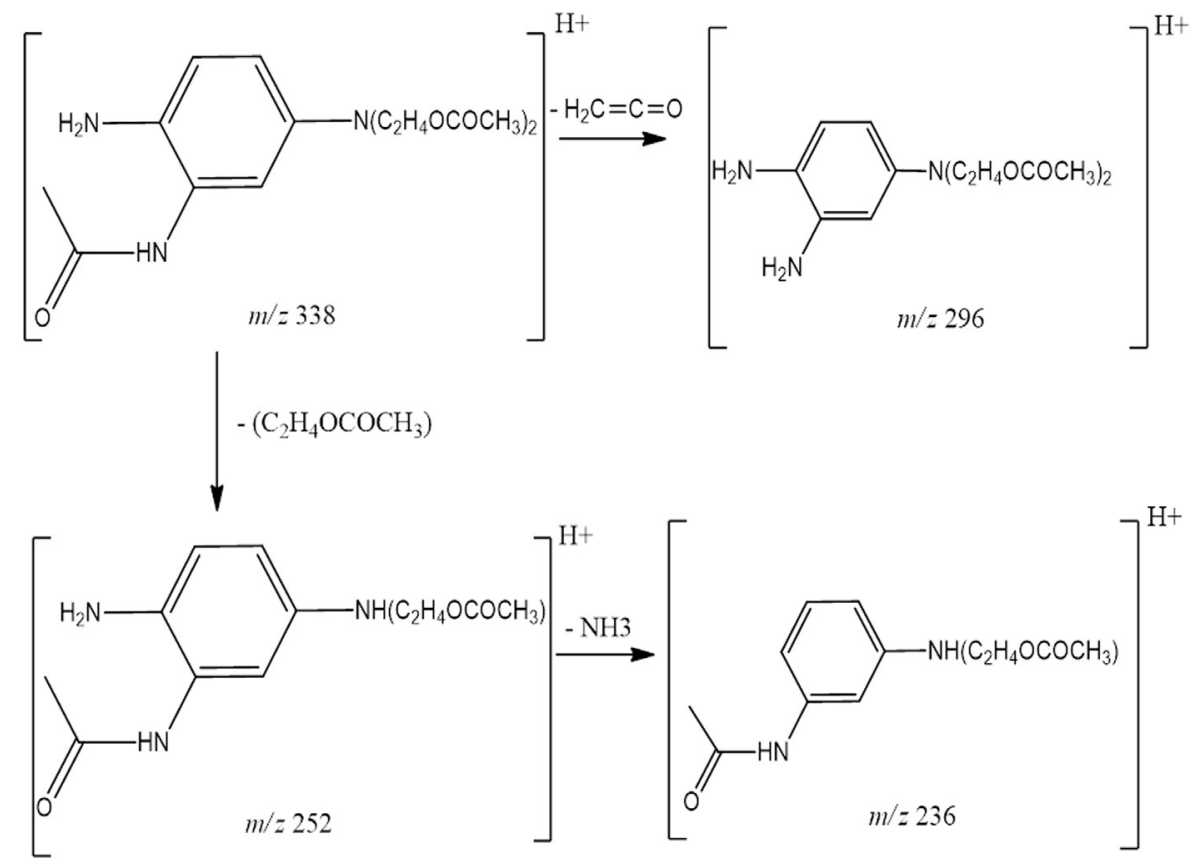

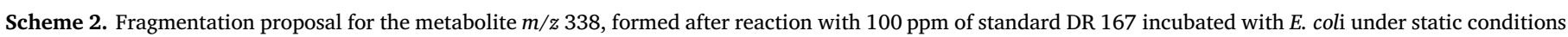
at $30{ }^{\circ} \mathrm{C}$ for seven days.

5 amino acid residues (Gln16, Ser15, Ser9, Ser17, Ser139) and one water molecule (Fig. S16). Despite having a lot of hydrogen bonds, DR 167 exhibited relatively higher interaction energy. This feature could, in principle, reinforce the rationalization that hydrogen bonds are solely incapable of modulating the stability of the studied compounds in the enzyme active site. In view of that, other molecular interactions should be considered when it comes to stabilizing the ligand-protein complex.

\subsubsection{Semi-empirical results: Affinity}

To include electronic contributions to the binding mode of the previously studied dyes by docking techniques, PM6 semi-empirical calculations were performed in the azoreductase active site considering a radius of $5 \AA$ (see Table 2).

From the values described in Table 2, one will observe that DR 73 presented the lowest interaction energy. Part of this stabilization is related to the presence of electrostatic interactions (Fig. S14), which help to better accommodate the ligand in the active site. The energy difference found between DR 73 and DR 78 is about $3.52 \mathrm{kcal} \mathrm{mol}^{-1}$. DR 167 presented the highest energy value, with an energy difference of $5.72 \mathrm{kcal} \mathrm{mol}^{-1}$ in relation to the most reactive DR 73. Remarkably, the PM6 semi-empirical results followed the same trend of the molecular docking data.

\subsubsection{Reactivity and molecular orbital analysis}

The concept of Effective Frontier Molecular Orbital (FERMO) for chemical reactions has been introduced recently (da Silva et al., 2006). This concept emerges as a powerful and innovative technique that allows the investigation of the role of molecular orbitals (MOs) applied to the description of breakage and formation of chemical bonds. In fact, the FERMO concept comes from a dose of chemical intuition and mathematical criteria for the composition and location of reactant molecular orbitals. In order to illustrate the FERMO assessment, the orbitals scheme is presented in Fig. S17, while the orbital energy values for the azo group are described in Table S1.

The energy values reported in Table S1 are readily in line with the molecular docking results as well as the affinity calculations at the semi-empirical level. The FERMO values are known to be related to the energy values of unoccupied orbitals which are susceptible to interaction during biotransformation reactions. Bearing in mind that a lower energy value of the unoccupied orbital FERMO is associated with a higher probability of reaction, DR 73 seems to be the most reactive compound owing to its lowest FERMO energy, $-2.27 \mathrm{eV}$. While the FERMO energy recorded a relatively higher increase in DR 78, DR 167 presented the largest value, $-1.79 \mathrm{eV}$. These data are in line with the high energy values obtained for both dyes in docking and semi-empirical calculations. Although the distribution of the orbitals is homogeneous among the studied compounds, the substituents bonded to the

Table 2

Semi-empirical values of $\mathrm{E}_{\mathrm{int}}$ and docking results for different dyes in the active site of azoreductase derived from Escherichia coli.

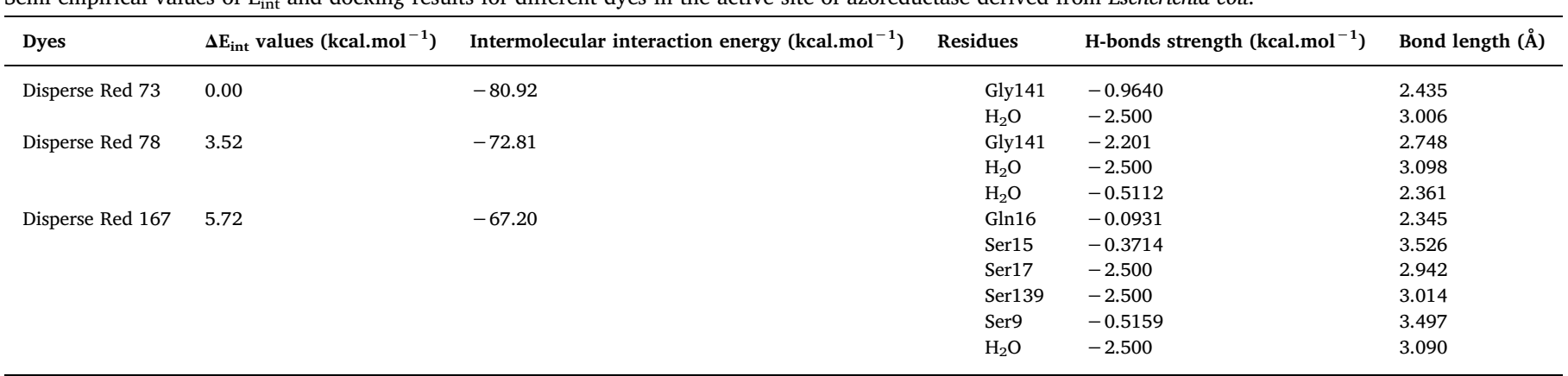


azo group, however, modulate variations in volume and energy of the molecular orbitals (Fig. S17).

Another fact that deserves mentioning is that the FERMO contributes towards the interaction between the dye and macromolecule. Thus, these results show that Disperse Red 73 possesses superior reactivity relative to the other two dyes (Table S1). This finding, in essence, brings valuable information to the fore besides being in agreement with the mutagenic effect evaluated and obtained through the use of Salmonella typhimurium (Ames test) described by Franco et al. (Franco et al., 2018).

\section{Discussion}

The gastrointestinal tract is undoubtedly a vital metabolic organ. Anaerobic bacteria are one of the major agents responsible for the metabolization of a wide variety of compounds, including azo dyes (Chung et al., 1975). The intestinal microflora plays the important role of metabolizing endogenous or exogenous compounds into mutagenic and/or carcinogenic substances that may cause the incidence of certain cancer (Yahagi et al., 1975; Roxon and Ryan, 1967).

The azo-reduction reaction plays a significant role in the mutagenesis and/or carcinogenesis of azo dyes, such as those studied in the present work. Indeed, it has proven to be the most important metabolic reaction of this type of dye.

Humans and other living beings may consume food or water contaminated with dyes or other polluting agents (de Aragão Umbuzeiro et al., 2005). The dye ingested can be biotransformed inside these living organisms. The metabolite (final product) obtained following the biotransformation will largely depend on the chemical structure of the dye. This is clearly in consonance with the idea that genotoxic effects are related to the high electrophilic nature of a substance or its products. The final product may also depend on the activation and detoxification of the dye molecules, which generally occur after the azo reduction, producing compounds that are more or less toxic than the original ones (Chung, 1983; Ben Mansour et al., 2007).

The results of this study prove that subjecting the disperse dyes that bear an azo group as the chromophore to culture medium with anaerobic or facultative bacteria, such as $E$. coli, promotes cleavage of the azo bond; this, consequently, leads to the formation of two amines which occurs possibly through the action of azoreductase. Although azoreductase can produce several enzymes, the abundant nature of this microorganism in the gut microbiota makes it conceivably the most noteworthy reductases for azo dye biotransformations. Considering the presence of azo bond in these dyes, azoreductase is probably the microorganism that works most effectively during the reaction with DR 73, DR 78, and DR 167, producing nitrobenzamines after biotransformation.

Nitrobenzamines are among the products obtained following the reaction of the dyes with $E$. coli. These aromatic amines are commonly obtained from the biodegradation of azo dyes under anaerobic conditions and may be derived from the reductive cleavage of azo bonds by microorganisms present in wastewater (Khalid et al., 2009). According to Cottalasso et al. (Cottalasso et al., 1991), 2- chloro-4-nitro-benzamine induces cell death in isolated rat hepatocytes, thereby causing microsomal damage. Other researchers have shown that 2-chloro-4nitro-benzamine is mutagenic to the Salmonella strains TA98NR, YG1020, YG1021, and YG1024 (Espinosa-Aguirre et al., 1991). The compound can also cause the failure of the DNA repair system (Uliana et al., 2013).

Electrophilicity increases the probability of a molecule reacting with nucleophilic DNA centers to generate adducts. When this genotoxic effect is not repaired, it may permanently change the DNA and generate a mutagenic effect (Ferraz et al., 2011; Osugi et al., 2009).

Due to the increased use of textile dyes each year, it is extremely important to understand the structure-activity relationships not only in determining the mutagenicity and/or carcinogenicity of this group of compounds, but also in the development of safe compounds for industrial applications (Chung and Cerniglia, 1992). The results of our investigation confirmed the structure-mutagenicity relationships between the metabolites obtained by in vitro biotransformation and the computational study aided us in relating the mutagenicity of the dyes to their chemical structure and the active site of the enzyme produced by Escherichia coli. While the relevance of the results reported here and those of other studies published in the literature needs not be overemphasized, further research is required so as to deepen our understanding on the mutagenicity and carcinogenicity of azo compounds, with special reference to textile dyes and their hazardous effects on the environment, humans and other living beings.

\section{Conclusion}

The biotransformation experiments conducted in this study show that $E$. coli bacteria promote complete cleavage of disperse dyes bearing an azo group. This is probably as a result of the action of an azoreductase. The cleavage leads to the formation of 3-4-aminophenylethyl-amino-propanitrile derived from both DR 73 and DR 78. 4-nitroaniline and 2-chloro-4-nitroaniline are the main products of DR 73 and DR 78 biotransformation, respectively. The results indicate the loss of the $\mathrm{CN}^{-}$group by $\mathrm{DR}$ 73. The main products of DR 167 biotransformation are dimethyl 3,3'-3-acetamido-4-aminophenyl-azanedyl-dipropanoato and 2-chloro-4-nitroaniline.

All the compounds identified in this work as potential metabolites of textile dyes have been classified as possible human carcinogens (2B) by the International Agency for Research on Cancer (IARC Working Group on the Evaluation of Carcinogenic Risks to Humans, 2007). Our results are in line with the recommendation of the European Union Countries, which prohibits the importation and marketing of products that could produce carcinogenic amines at ppm levels (European Community, Commission Decision, 2002).

Clearly, theoretical studies have brought great contribution to the understanding of the interaction and reactivity of the studied dyes. Our findings show that all the dyes investigated here presented a quite favorable binding mode in the active site of the azoreductase produced by Escherichia coli. As such, they are likely to undergo biotransformation by means of this enzyme. These results are strictly in agreement with the FERMO analysis. The hydrogen bonds in addition to the structural and electronic effects evaluated through the docking and semi-empirical calculations modulate the binding mode between the dyes and the enzyme. In fact, based on both the docking and semi-empirical calculations, Disperse Red 73 exhibited the best intermolecular interaction energy value with the azoreductase active site.

To sum up, the results point out that both the original textile dyes and their degradation products may pose serious risks to human health and the environment at large. Considering that the reduction steps used in this work mimic endogenous reactions, toxic compounds may emerge from the human liver and gastrointestinal tract after oral exposure to DR 73, DR 78, and DR 167.

\section{Acknowledgements}

The authors gratefully acknowledge the financial support granted by the Brazilian research funding agencies including CNPq, CAPES, FAPEMIG and FAPESP (2008/10449-7 and 2015/18109-4).

\section{Appendix A. Supplementary material}

Supplementary data associated with this article can be found in the online version at http://dx.doi.org/10.1016/j.ecoenv.2018.04.066.

\section{References}

Ben Mansour, H., Corroler, D., Barillier, D., Ghedira, K., Chekir, L., Mosrati, R., 2007. 
Evaluation of genotoxicity and pro-oxidant effect of the azo dyes: acids yellow 17, violet 7 and orange 52, and of their degradation products by Pseudomonas putida mt2. Food Chem. Toxicol. 45, 1670-1677. http://dx.doi.org/10.1016/j.fct.2007.02. 033

Brandon, E.F., Raap, C.D., Meijerman, I., Beijnen, J.H., Schellens, J.H., 2003. An update on in vitro test methods in human hepatic drug biotransformation research: pros and cons. Toxicol. Appl. Pharmacol. 189, 233-246. http://dx.doi.org/10.1016/S0041008X(03)00128-5.

Brown, J.P., 1981. Reduction of polymeric azo and nitro dyes by intestinal bacteria. Appl. Environ. Microbiol. 41, 1283-1286.

Brüschweiler, B.J., Küng, S., Bürgi, D., Muralt, L., Nyfeler, E., 2014. Identification of nonregulated aromatic amines of toxicological concern which can be cleaved from azo dyes used in clothing textiles. Regul. Toxicol. Pharmacol. 69, 263-272. http://dx.doi. org/10.1016/j.yrtph.2014.04.011.

Cerniglia, C.E., Freeman, J.P., Franklin, W., Pack, L.D., 1982. Metabolism of azo dyes derived from benzidine, 3,3'-dimethylbenzidine and 3,3' -dimethoxybenzidine to potentially carcinogenic aromatic amines by intestinal bacteria. Carcinogenesis 3 , 1255-1260. http://dx.doi.org/10.1093/carcin/3.11.1255.

Cerniglia, C.E., Zhuo, Z., Manning, B.W., Federle, T.W., Heflich, R.H., 1986. Mutagenic activation of the benzidine-based dye Direct Black 38 by human intestinal microflora. Mutat. Res. Lett. 175, 11-16. http://dx.doi.org/10.1016/0165-7992(86)90138-7.

Chung, K.-T., 1983. The significance of azo-reduction in the mutagenesis and carcinogenesis of azo dyes. Mutat. Res. Genet. Toxicol. 114, 269-281. http://dx.doi.org/10. 1016/0165-1110(83)90035-0.

Chung, K.-T., Cerniglia, C.E., 1992. Mutagenicity of azo dyes: structure-activity relationships. Mutat. Res. Genet. Toxicol. 277, 201-220. http://dx.doi.org/10.1016/ 0165-1110(92)90044-A.

Chung, K.-T., Fulk, G.E., Slein, M.W., 1975. Tryptophanase of fecal flora as a possible factor in the etiology of colon Cancer23. JNCI J. Natl. Cancer Inst. 54, 1073-1078. http://dx.doi.org/10.1093/jnci/54.5.1073.

Chung, K.-T., Stevens, S.E., 1993. Degradation azo dyes by environmental microorganisms and helminths. Environ. Toxicol. Chem. 12, 2121-2132. http://dx.doi.org/10 1002/etc.5620121120.

Cottalasso, D., Pronzato, M.A., Domenicotti, C., Barisione, G., Fontana, L., Nanni, G, 1991. [Toxicity of 4-chloro-2-nitroaniline and 2-chloro-4-nitroaniline to isolated rat hepatocytes]. Med. Lav. 82, 253-260.

da Cunha, E.F.F., Mancini, D.T., Ramalho, T.C., 2012. Molecular modeling of the Toxoplasma gondii adenosine kinase inhibitors. Med. Chem. Res. 21, 590-600. http://dx.doi.org/10.1007/s00044-011-9554-z.

da Cunha, E.F.F., Martins, R.C.A., Albuquerque, M.G., de Alencastro, R.B., 2004. LIV-3DQSAR model for estrogen receptor ligands. J. Mol. Model. 10, 297-304. http://dx. doi.org/10.1007/s00894-004-0198-5.

da Silva, R.R., Ramalho, T.C., Santos, J.M., Figueroa-Villar, J.D., 2006. On the limits of highest-occupied molecular orbital driven reactions: the frontier effective-for-reaction molecular orbital concept. J. Phys. Chem. A 110, 1031-1040. http://dx.doi.org/ 10.1021/jp054434y.

de Aragão Umbuzeiro, G., Freeman, H.S., Warren, S.H., de Oliveira, D.P., Terao, Y., Watanabe, T., Claxton, L.D., 2005. The contribution of azo dyes to the mutagenic activity of the Cristais River. Chemosphere 60, 55-64. http://dx.doi.org/10.1016/j chemosphere.2004.11.100

de Aragão Umbuzeiro, G., Roubicek, D.A., Rech, C.M., Sato, M.I.Z., Claxton, L.D., 2004. Investigating the sources of the mutagenic activity found in a river using the Salmonella assay and different water extraction procedures. Chemosphere 54, 1589-1597. http://dx.doi.org/10.1016/j.chemosphere.2003.09.009.

dos Santos, A.B., Cervantes, F.J., van Lier, J.B., 2007. Review paper on current technologies for decolourisation of textile wastewaters: perspectives for anaerobic biotechnology. Bioresour. Technol. 98, 2369-2385. http://dx.doi.org/10.1016/j. biortech.2006.11.013.

Elisangela, F., Andrea, Z., Fabio, D.G., de Menezes Cristiano, R., Regina, D.L., Artur, C.-P., 2009. Biodegradation of textile azo dyes by a facultative Staphylococcus arlettae strain $\mathrm{VN}-11$ using a sequential microaerophilic/aerobic process. Int. Biodeterior. Biodegrad. 63, 280-288, http://dx doi.org/10.1016/j.ibiod 2008.10.003.

Espinosa-Aguirre, J., Reyes, R., Cortinas de Nava, C., 1991. Mutagenic activity of 2chloro-4-nitroaniline and 5-chlorosalicylic acid in Salmonella typhimurium: two possible metabolites of niclosamide. Mutat. Res. Lett. 264, 139-145. http://dx.doi. org/10.1016/0165-7992(91)90131-M.

Ferraz, E.R.A., Umbuzeiro, G.A., De-Almeida, G., Caloto-Oliveira, A., Chequer, F.M.D., Zanoni, M.V.B., Dorta, D.J., Oliveira, D.P., 2011. Differential toxicity of Disperse Red 1 and Disperse Red 13 in the Ames test, HepG2 cytotoxicity assay, and Daphnia acute toxicity test. Environ. Toxicol. 26, 489-497. http://dx.doi.org/10.1002/tox.20576.

Franciscon, E., Piubeli, F., Fantinatti-Garboggini, F., Ragagnin de Menezes, C., Serrano Silva, I., Cavaco-Paulo, A., Grossman, M.J., Durrant, L.R., 2010. Polymerization study of the aromatic amines generated by the biodegradation of azo dyes using the laccase enzyme. Enzym. Microb. Technol. 46, 360-365. http://dx.doi.org/10.1016/j enzmictec. 2009.12.014

Franco, J.H., Silva, B.F. da, Oliveira, R.V., Meireles, G., de Oliveira, D.P., Castro, A.A. de, Ramalho, T.C., Zanoni, M.V.B., 2018. Identification of biotransformation products of disperse dyes with rat liver microsomes by LC-MS/MS and theoretical studies with DNA: structure-mutagenicity relationship using Salmonella /microsome assay. Sci. Total Environ. 613-614, 1093-1103. http://dx.doi.org/10.1016/j.scitotenv.2017.08. 271.

Golob, V., Tušek, L., 1999. VIS absorption spectrophotometry of disperse dyes. Dyes Pigment. 40, 211-217. http://dx.doi.org/10.1016/S0143-7208(98)00055-2.

Gonçalves, A., da, S., França, T.C.C., Figueroa-Villar, J.D., Pascutti, P.G., 2011. Molecular dynamics simulations and QM/MM studies of the reactivation by 2-PAM of tabun inhibited human acethylcolinesterase. J. Braz. Chem. Soc. 22, 155-165. http://dx.
doi.org/10.1590/S0103-50532011000100021.

Govindwar, S.P., Kurade, M.B., Tamboli, D.P., Kabra, A.N., Kim, P.J., Waghmode, T.R., 2014. Decolorization and degradation of xenobiotic azo dye Reactive Yellow-84A and textile effluent by Galactomyces geotrichum. Chemosphere 109, 234-238. http://dx. doi.org/10.1016/j.chemosphere.2014.02.009.

Guimarães, A.P., França, T.C.C., Ramalho, T.C., Rennó, M.N., da Cunha, E.F.F., Matos, K.S., Mancini, D.T., Kuča, K., 2011. Docking studies and effects of syn-anti isomery of oximes derived from pyridine imidazol bicycled systems as potential human acetylcholinesterase reactivators. J. Appl. Biomed. 9, 163-171. http://dx.doi.org/10. 2478/v10136-009-0037-1.

Hur, S., Bruice, T.C., 2003. The near attack conformation approach to the study of the chorismate to prephenate reaction. Proc. Natl. Acad. Sci. 100, 12015-12020. http:// dx.doi.org/10.1073/pnas.1534873100.

IARC Working Group on the Evaluation of Carcinogenic Risks to Humans, 2007. Human papillomaviruses. IARC Monogr. Eval. Carcinog. Risks to Humans, 90, pp. 1-636.

Ito, K., Nakanishi, M., Lee, W.-C., Sasaki, H., Zenno, S., Saigo, K., Kitade, Y., Tanokura, M., 2006. Three-dimensional structure of AzoR from Escherichia coli: an oxidereductase conserved in microorganisms. J. Biol. Chem. 281, 20567-20576. http://dx. doi.org/10.1074/jbc.M513345200.

Khalid, A., Arshad, M., Crowley, D.E., 2009. Biodegradation potential of pure and mixed bacterial cultures for removal of 4-nitroaniline from textile dye wastewater. Water Res. 43, 1110-1116. http://dx.doi.org/10.1016/j.watres.2008.11.045.

Kunz, A., Peralta-Zamora, P., Moraes, S.G. de, Durán, N., 2002. Novas tendências no tratamento de efluentes têxteis. Quim. Nova 25, 78-82. http://dx.doi.org/10.1590/ S0100-40422002000100014.

Levine, W.G., 1985. Studies on microsomal azoreduction: n,n-dimethyl-4-aminoazobenzene (DAB) and its derivatives. Biochem. Pharmacol. 34, 3259-3264. http://dx. doi.org/10.1016/0006-2952(85)90343-0.

Lewars, E.G., 2011. Computational Chemistry, Computational Chemistry: Introduction to the Theory and Applications of Molecular and Quantum Mechanics. Springer, Netherlands, Dordrecht. http://dx.doi.org/10.1007/978-90-481-3862-3.

Lewis, D.M., 2008. Coloration in the next century. Rev. Prog. Color. Relat. Top. 29, 23-28. http://dx.doi.org/10.1111/j.1478-4408.1999.tb00124.x.

Luo, J., Bruice, T.C., 2004. Anticorrelated motions as a driving force in enzyme catalysis: the dehydrogenase reaction. Proc. Natl. Acad. Sci. 101, 13152-13156. http://dx.doi. org/10.1073/pnas.0405502101.

Matos, K.S., Mancini, D.T., Cunha, E.F.F., da, Kuča, K., França, T.C.C., Ramalho, T.C., 2011. Molecular aspects of the reactivation process of acetylcholinesterase inhibited by cyclosarin. J. Braz. Chem. Soc. 35, 89-95. http://dx.doi.org/10.1590/S010350532011001000023.

Morgon, N.H., Coutinho, K., 2007. Métodos de Química Teórica e Modelagem Molecular. Editora Livraria da Física, São Paulo.

Novotný, Č., Dias, N., Kapanen, A., Malachová, K., Vándrovcová, M., Itävaara, M., Lima, N., 2006. Comparative use of bacterial, algal and protozoan tests to study toxicity of azo- and anthraquinone dyes. Chemosphere 63, 1436-1442. http://dx.doi.org/10. 1016/j.chemosphere.2005.10.002.

Ogawa, T., Idaka, E., Kumazaki, T., 1978. Effects of substituents of some aromatic compounds and particularly of acid azo dyes on the respiratory inhibition of microbial populations in activated sludge. Sen'i Gakkaishi 34, T212-T215. http://dx.doi.org/ 10.2115/fiber.34.5_T212.

Oliveira, D.P., Carneiro, P.A., Rech, C.M., Zanoni, M.V.B., Claxton, L.D., Umbuzeiro, G.A., 2006. Mutagenic compounds generated from the chlorination of disperse azo-dyes and their presence in drinking water. Environ. Sci. Technol. 40, 6682-6689. http:// dx.doi.org/10.1021/es061020p.

Osugi, M.E., Rajeshwar, K., Ferraz, E.R.A., de Oliveira, D.P., Araújo, Â.R., Zanoni, M.V.B., 2009. Comparison of oxidation efficiency of disperse dyes by chemical and photoelectrocatalytic chlorination and removal of mutagenic activity. Electrochim. Acta 54, 2086-2093. http://dx.doi.org/10.1016/j.electacta.2008.07.015.

Osugi, M.E., Umbuzeiro, G.A., De Castro, F.J.V., Zanoni, M.V.B., 2006. Photoelectrocatalytic oxidation of remazol turquoise blue and toxicological assessment of its oxidation products. J. Hazard. Mater. 137, 871-877. http://dx.doi.org/10. 1016/j.jhazmat.2006.03.036.

Rafii, F., Hall, J.D., Cerniglia, C.E., 1997. Mutagenicity of azo dyes used in foods, drugs and cosmetics before and after reduction by Clostridium species from the human intestinal tract. Food Chem. Toxicol. 35, 897-901. http://dx.doi.org/10.1016/S02786915(97)00060-4.

Ramalho, T.C., Rocha, M.V.J., da Cunha, E.F.F., Oliveira, L.C.A., Carvalho, K.T.G., 2010. Understanding the molecular behavior of organotin compounds to design their effective use as agrochemicals: exploration via quantum chemistry and experiments. J. Biomol. Struct. Dyn. 28, 227-238. http://dx.doi.org/10.1080/07391102.2010. 10507355.

Roxon, J.J., Ryan, A.J., 1967. Reduction of water-soluble azo dyes by intestinal bacteria Food Cosmet. Toxicol. 5, 367-369. http://dx.doi.org/10.1016/S0015-6264(67) 83064-5.

Şahin, S., Demir, C., Güçer, Ş., 2007. Simultaneous UV-vis spectrophotometric determination of disperse dyes in textile wastewater by partial least squares and principal component regression. Dyes Pigment. 73, 368-376. http://dx.doi.org/10.1016/j dyepig.2006.01.045.

Saratale, R.G., Saratale, G.D., Chang, J.S., Govindwar, S.P., 2011. Bacterial decolorization and degradation of azo dyes: a review. J. Taiwan Inst. Chem. Eng. 42, 138-157. http://dx.doi.org/10.1016/j.jtice.2010.06.006.

Silva, T.C., de Almeida, K.J., dos Santos Pires, M., de Castro, A.A., Gonçalves, M.A., da Cunha, E.F.F., Ramalho, T.C., 2017. Theoretical structural and electronic analyses with emphasis on the reactivity of iron oxide prototypes in methane $\mathrm{C}-\mathrm{H}$ bond activation. React. Kinet. Mech. Catal. 120, 195-208. http://dx.doi.org/10.1007/ s11144-016-1103-9. 
Silva, T.C., dos Santos Pires, M., de Castro, A.A., da Cunha, E.F.F., Caetano, M.S., Ramalho, T.C., 2015. Molecular insight into the inhibition mechanism of plant and rat 4-hydroxyphenylpyruvate dioxygenase by molecular docking and DFT calculations. Med. Chem. Res. 24, 3958-3971. http://dx.doi.org/10.1007/s00044-0151436-3.

Sweeney, E.A., Chipman, J.K., Forsythe, S.J., 1994. Evidence for direct-acting oxidative genotoxicity by reduction products of azo dyes. Environ. Health Perspect. 102, 119-122. http://dx.doi.org/10.1289/ehp.94102s6119.

Thomsen, R., Christensen, M.H., 2006. MolDock: a new technique for high-accuracy molecular docking. J. Med. Chem. 49, 3315-3321. http://dx.doi.org/10.1021/ jm051197e.

Uliana, C.V., Garbellini, G.S., Yamanaka, H., 2013. Evaluation of the interactions of DNA with the textile dyes Disperse Orange 1 and Disperse Red 1 and their electrolysis products using an electrochemical biosensor. Sens. Actuators B Chem. 178, 627-635. http://dx.doi.org/10.1016/j.snb.2013.01.029.

Yahagi, T., Degawa, M., Seino, Y., Matsushima, T., Nagao, M., Sugimura, T., Hashimoto, Y., 1975. Mutagenicity of carcinogenic azo dyes and their derivatives. Cancer Lett. 1, 91-96. http://dx.doi.org/10.1016/S0304-3835(75)95563-9.

Zanoni, T.B., Lizier, T.M., Assis, M., das, D., Zanoni, M.V.B., de Oliveira, D.P., 2013. CYP450 isoenzymes catalyze the generation of hazardous aromatic amines after reaction with the azo dye Sudan III. Food Chem. Toxicol. 57, 217-226. http://dx.doi.org/10. 1016/j.fct.2013.03.035.

Zimmermann, T., Kulla, H.G., Leisinger, T., 1982. Properties of purified orange II azoreductase, the enzyme initiating azo dye degradation by pseudomonas KF46. Eur. J. Biochem. 129, 197-203. http://dx.doi.org/10.1111/j.1432-1033.1982.tb07040.x. 